\title{
Neonatal Jaundice Risk Factors at a District Hospital in Rwanda
}

\author{
Claudine Murekatete ${ }^{1 *}$, Claudine Muteteli ${ }^{1}$, Richard Nsengiyumva ${ }^{1}$, Geldine Chironda ${ }^{1,2,3}$ \\ ${ }_{1}^{1}$ School of Nursing and Midwifery, College of Medicine and Health Sciences, University of Rwanda, Kigali, \\ Rwanda \\ ${ }^{2}$ Rory Meyers College of Nursing, New York University, New York, USA \\ ${ }^{3}$ School of Nursing and Public Health, College of Health Sciences, University of KwaZulu Natal, Durban, South \\ Africa
}

*Corresponding author: Claudine Murekatete. School of Nursing and Midwifery, College of Medicine and Health Sciences, University of Rwanda, Remera Campus, 11 KG 47, Kigali, Rwanda. Email: tetaclaudin@gmail.com

\section{ABSTRACT}

\section{Background}

Neonatal jaundice is one of the most common reasons for hospital admission in the neonatal unit, and it is associated with significant morbidity and mortality.

\section{Objective}

To assess risk factors associated with neonatal jaundice among newborns at a District Hospital in Rwanda.

\section{Methods}

A quantitative approach has been used with a retrospective cross-sectional design. Two hundred and ten files were used as sample size. Stratified proportional sampling was used for the years 2016-2018 to select files. Data was collected using a structured questionnaire. Descriptive statistics and inferential statistics were used for the data analysis.

\section{Results}

The study findings showed that nearly half $(44.3 \%)$ of 210 newborns were diagnosed with neonatal jaundice. The majority $(87.2 \%)$ was term, and male gender (60.5\%). Nearly a third $(29.5 \%)$ were Low Birth Weight. Significant risk factors for neonatal jaundice were birth weight $(p=0.015)$, gestational age of the newborn $(p=0.002)$, neonatal gender $(p=0.004)$, method of delivery $(p=.000)$, blood group incompatibility $(p=0.001)$; infections $(p$ $=0.000)$, cesarean section $(p=0.000)$ and prematurity $(p=0.017)$.

\section{Conclusion}

There was a high prevalence of neonatal jaundice. Neonatal jaundice risk factors were predominantly demographic, maternal and neonatal. Hence there is need to formulate tailored interventions that mitigate neonatal jaundice.

Rwanda J Med Health Sci 2020;3(2):204-213.

Keywords: Neonatal jaundice, risk factors, newborn, district hospital, Rwanda

\section{BACKGROUND}

Neonatal jaundice is a condition that affects $60 \%$ $80 \%$ of newborns worldwide.[1] Though most neonates experience mild jaundice, a Global Burden of Disease (GBD) study in 2016 showed that neonatal jaundice accounted for 1,008 deaths per 100,000 live births and ranked seventh in mortality during the early-neonatal period (0 - 6 days).[2] Severe hyperbilirubinemia is estimated to affect 1.1 million neonates every year in South Asia and subSaharan Africa (SSA), where it is ranked the 7th and eighth leading cause of neonatal mortality, respectively.[3] In South Africa, the prevalence of neonatal jaundice was $55.2 \%,[1]$ whereas, in Pakistan, the prevalence of neonatal jaundice was $27.6 \% \cdot[4]$

Severe hyperbilirubinemia, with or without encephalopathy, is associated with substantial mortality and long-term morbidity in low-tomoderate income countries (LMIC),[5] including Rwanda. High levels of bilirubin can cause permanent brain damage (kernicterus), and therefore screening and prompt treatment are important strategies.[5] At three years of age, full neurological symptoms of kernicterus, including 
bilateral athetosis with involuntary muscular spasms, extrapyramidal symptoms, seizure, mental retardation, dysarthria, high-frequency hearing loss, and strabismus and eye movement abnormalities can appear.[5]

Another study conducted on the magnitude of neonatal jaundice and in a NICU in Mekelle City Public Hospitals, Northern Ethiopia, revealed that risk factors such as prolonged duration of labor, male neonates, and "O" blood group was associated with neonatal jaundice.[6] A study conducted hyperbilirubinemia in newborns in Kaiser Permanente Northern California showed that boys, nonwhite, large for gestational age, and of lower gestational age were associated with neonatal jaundice.[7]

Rwanda Health Sector has registered significant achievements in the previous years. However, challenges need to be addressed to improve the quality of service delivery for the prevention and control of some conditions. The identification of needs and a concerted effort to improve management at different levels of the health system can significantly reduce acute bilirubin encephalopathy (ABE) and improve opportunities for thousands of newborns around the world.[8] Rwanda, as one of the LMIC, needs to know the prevalence and risk factors associated with neonatal jaundice to reinforce the existing policies in maternal and neonatal child health. Risk factors like maternal, prenatal, and neonatal are significantly or not significantly associated with severe hyperbilirubinemia in LMIC.[9]

Several studies have identified factors associated with neonatal jaundice. A study conducted in Iran addressed the complications of neonatal jaundice and predisposing factors in newborns with idiopathic jaundice, $\mathrm{ABO}$ incompatibility, $\mathrm{Rh}$ incompatibility, and G6PD deficiency as risk factors.[5] A study in Southern Nepal indicated that male gender, high birth weight, breastfeeding, warm ambient temperature, primiparity, skilled birth attendance, place of delivery, prolonged labor, oil massage, paternal education, and ethnicity were critical risk factors.[10] However, data about the prevalence and related risk factors in Rwanda are limited.[3]

In Rwanda, the only study conducted at Ruhengeri district hospital identified a high prevalence of neonatal jaundice, which was $41.3 \%$, and the risk factors of pathologic hyperbilirubinemia in the same hospital were maternal age, birth weight and the number of parity.[3] The author of the only research conducted on neonatal jaundice in Rwanda recommended that other research studies should be conducted across the country to confirm the prevalence of pathologic hyperbilirubinemia in newborns. The present study assessed the prevalence and risk factors associated with neonatal jaundice at a selected district hospital of Rwanda.

\section{METHODS}

\section{Design}

A retrospective design was used to collect data from the files of newborns admitted in the neonatal unit of Kabgayi District Hospital in Muhanga District during 2016-2018. The study was conducted between 05 March and 31 May 2019.

\section{Study setting}

The study was conducted in the neonatology ward at Kabgayi District Hospital in the Southern Province, Muhanga District. The setting was selected as it had over a dozen cases of neonatal jaundice admitted in the neonatal unit in a twoweek period.

\section{Inclusion and exclusion criteria}

The inclusion criteria were all newborns born and later readmitted to the neonatal unit of Kabgayi District Hospital in Muhanga District during 20162018. Exclusion criteria were newborns admitted before or after the designated dates or born at other health facilities.

\section{Sample size}

The formula of Taro Yamane (1967) to calculate the sample size of newborns for representing all newborns admitted to the hospital has been used. $\mathrm{n}=\mathrm{N} / 1+\mathrm{N}^{*}(\mathrm{e}){ }^{2}$ where $\mathrm{n}=$ Sample size; $\mathrm{n}=$ the population size; $\mathrm{e}=$ the acceptable sampling error $(e=0.05)$. The population of this study included 160 newborns in 2016, 157 in 2017, and 125 in 2018 for a total population of 442 . The sample size was $442 / 1+442 *(0.05)^{2}=210$ newborns.

\section{Sampling strategy}

A stratified proportional sampling for newborns born and readmitted at the hospital in 2016- 2018.

\section{Measures}

A modified data collection tool from Brits et al (2018), who conducted a similar study on the prevalence of neonatal jaundice and risk factors in healthy term neonates [1], has been used with permission to collect data needed to answer the research questions. The tool was modified and adapted to the Rwandan context, with the removal 
of the mother's race and the primiparity. Other items on the tool have been maintained, as they were applicable in the Rwandan context. The data collection tool had two sections:

Section 1: Demographic data of the newborn and mother (4 items) - maternal age (years), neonatal gender, birth weight (grams), age of admission to the neonatal unit (days) and participants medical diagnosis.

Section 2: Risk factors of the mother (7 items) and neonate (10 items). Maternal - labor induction with oxytocin, premature rupture of membranes (PROM), delivery method, and oral contraceptive use in pregnancy, alcohol use in pregnancy, sibling jaundice, and ABO incompatibility. Neonatal prematurity, gestational age (weeks), not breastfeeding $\leq$ hour post-birth, ABO, and other blood group incompatibilities, infection, cephalohematoma, and early hospital discharge.

\section{Validity and reliability of the data collection tool}

The tool was submitted to an expert nurse with Doctorate in Nursing Practitioner (DNP) in neonatology science for a face validation to confirm if the tool would be measuring what it was supposed to measure (the prevalence and risk factors of neonatal jaundice). The tool was piloted on 10 cases admitted in the neonatal unit in 2018. For this study, Cronbach's alpha has been used to determine internal consistency. The tool had 22 items, and the Cronbach's alpha test was 0.856 meaning the instrument was a very good measure of concepts under study.

\section{Data collection}

After the permission of the University of Rwanda and the district hospital, the investigator reviewed the births recorded in the 2016 -2018 neonatal files. The information was retrieved from the neonatal files in the registry of the hospital.

\section{Data analysis}

Data were analyzed using SPSS software version 23. The data analysis used descriptive statistics in the form of percentages and frequencies was used to describe the demographic data of the child and the mother, the maternal and neonatal risk factors. Chisquare test was used to establish any association between demographics, neonatal, and maternal risk factors and neonatal jaundice. A p-value of $<0.05$ was statistically significant.

\section{Ethical considerations}

An ethical clearance from the University of Rwanda, College of Medicine and Health Sciences, Institutional Review Board (IRB), and the recommendation from the Ministry of Health $(\mathrm{MOH})$ was obtained. The approval from the study site had also been obtained.

\section{RESULTS}

\section{Demographic characteristics}

Table 1 displays results on maternal age, gender, birth weight, and postnatal age.

Table 1. Demographic data of mother and newborn $(n=210)$

\begin{tabular}{llll}
\hline Demographic variables of the baby & frequency & Percentage \\
\hline New-born age of admission in & $\leq 7$ days & 176 & $83.8 \%$ \\
neonatal unit(days) & >7days & 34 & $16.2 \%$ \\
\multirow{4}{*}{ Gender } & Total & $\mathbf{2 1 0}$ & $\mathbf{1 0 0 \%}$ \\
& female & 83 & $39.5 \%$ \\
\multirow{3}{*}{ Birth weight } & male & 127 & $60.5 \%$ \\
& Total & $\mathbf{2 1 0}$ & $\mathbf{1 0 0} \%$ \\
& $1501 \mathrm{~g}-2000 \mathrm{~g}$ & 1 & $0.5 \%$ \\
& & & \\
& $2001 \mathrm{~g}-2500 \mathrm{~g}$ & 62 & $29.5 \%$ \\
& 2501g-3000g & 147 & $70 \%$ \\
& Total & $\mathbf{2 1 0}$ & $\mathbf{1 0 0} \%$
\end{tabular}

Table 1 shows demographic data of neonates. The majority $(83.8 \%)$ of neonates were less or equal to 7 days and $16.2 \%$ with more than 7 days. There were $127(60.5 \%)$ males and $83(39.5 \%)$ 
females. For the birth weight, the majority range of weight for 210 participants was $2501 \mathrm{~g}-3000 \mathrm{~g}$ $147(70 \%), 1(0.5 \%)$ was in the range of $1501 \mathrm{~g}-2000 \mathrm{~g}$ of birth weight, and $62(29.5 \%)$ were in the range of $2001 \mathrm{~g}-2500 \mathrm{~g}$ of birth weight. For maternal age, the majority ranged from 25 to 34 years, $131(62.4 \%)$.

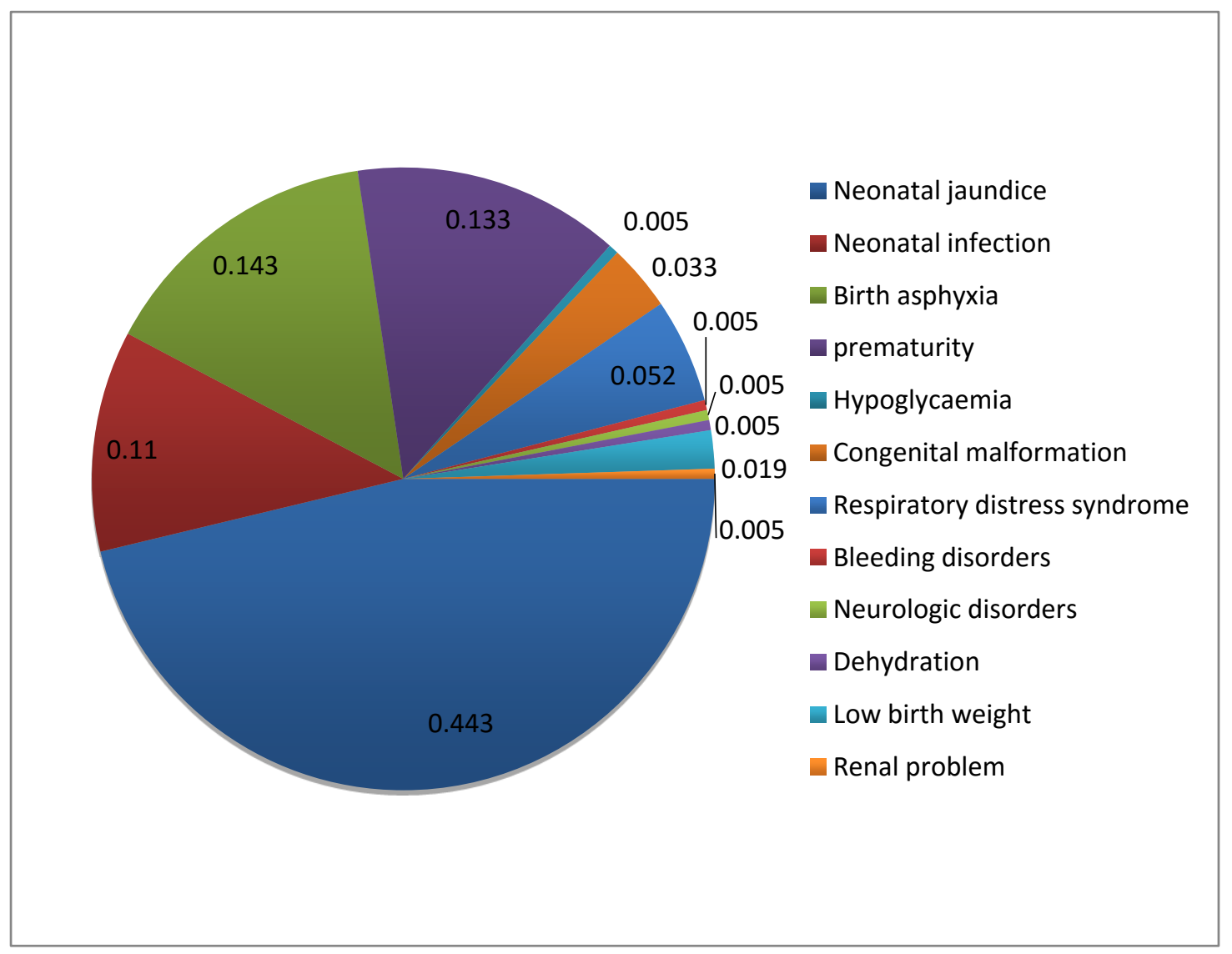

Figure 1. Prevalence of neonatal jaundice

An analysis of the participants' medical diagnosis in Figure 1 indicated that the majority of participants, 93 (44.3\%) were presenting with neonatal jaundice, 23(11.0\%), infection, 30(14.3\%) birth asphyxia, 28(13.3\%) prematurity, $11(5.2 \%)$ respiratory distress syndrome, $7(3.3 \%)$ congenital malformation, $4(1.9 \%) \mathrm{LBW}, 1(0.5 \%)$ hypoglycaemia, $1(0.5 \%)$ bleeding disorders, $1(0.5 \%)$ neurologic disorders, $1(0.5 \%)$ dehydration, $1(0.5 \%)$ and renal problems. Therefore, the results indicated the prevalence of neonatal jaundice among the studied population as $44.3 \%$. 
Maternal risk factors of neonatal jaundice

Table 2. Maternal risk factors of neonatal jaundice $(n=210)$

\begin{tabular}{|c|c|c|c|}
\hline Variables & & frequency & Percentage \\
\hline \multirow{4}{*}{$\begin{array}{ll}\text { Maternal age } & 15-24 \\
& 25-34 \\
& 35 \text { and more }\end{array}$} & Yes & 46 & $21.9 \%$ \\
\hline & Yes & 131 & $62.4 \%$ \\
\hline & Yes & 33 & $15.7 \%$ \\
\hline & Total & 210 & $100 \%$ \\
\hline \multirow{2}{*}{ Induction of labor with oxytocin } & No & 210 & $100 \%$ \\
\hline & Total & 210 & $100 \%$ \\
\hline \multirow[t]{3}{*}{ Method of delivering } & Natural & 104 & $49.5 \%$ \\
\hline & $\begin{array}{l}\text { C- } \\
\text { Section }\end{array}$ & 106 & $50.5 \%$ \\
\hline & Total & 210 & $100 \%$ \\
\hline \multirow[t]{3}{*}{ Oral contraceptive in pregnancy } & Yes & 0 & $0 \%$ \\
\hline & No & 210 & $100 \%$ \\
\hline & Total & 210 & $100 \%$ \\
\hline \multirow[t]{3}{*}{ Alcohol use during pregnancy } & Yes & 0 & $0 \%$ \\
\hline & No & 210 & $100 \%$ \\
\hline & Total & 210 & $100 \%$ \\
\hline \multirow[t]{3}{*}{ Sibling jaundice } & Yes & 0 & $0 \%$ \\
\hline & No & 210 & $100 \%$ \\
\hline & Total & 210 & $100 \%$ \\
\hline \multirow[t]{3}{*}{ ABO incompatibility } & Yes & 3 & $1.4 \%$ \\
\hline & No & 207 & $98.6 \%$ \\
\hline & Total & 210 & $100 \%$ \\
\hline \multirow[t]{3}{*}{ premature rupture of membranes } & Yes & 1 & $0.5 \%$ \\
\hline & No & 209 & $99.5 \%$ \\
\hline & Total & 210 & $100 \%$ \\
\hline
\end{tabular}

Table 2 shows results on the maternal risk factors of neonatal jaundice. For the method of delivery, the majority of mothers 106 (50.5\%) delivered by cesarean; 104 (49.5\%) delivered by natural method. For ABO incompatibility, only $3(1.4 \%)$ of mothers were presenting $\mathrm{ABO}$ incompatibility. For premature rupture of membranes, only one mother, $1(0.5 \%)$ had experienced the premature rupture of membranes.

Table 3. Neonatal risk factors of jaundice

\begin{tabular}{llll}
\hline Variables & & Frequency & Percent \\
& & & \\
ABO and other & No & 200 & $95.2 \%$ \\
blood group & Yes & 10 & $4.8 \%$ \\
incompatibilities & Total & $\mathbf{2 1 0}$ & $\mathbf{1 0 0 . 0} \%$ \\
& & 160 & $76.2 \%$
\end{tabular}




\begin{tabular}{|c|c|c|c|}
\hline & $\begin{array}{l}\text { Yes } \\
\text { Total }\end{array}$ & $\begin{array}{l}50 \\
\mathbf{2 1 0}\end{array}$ & $\begin{array}{l}23.8 \% \\
100.0 \%\end{array}$ \\
\hline \multirow[t]{3}{*}{ Prematurity } & No & 164 & $78.1 \%$ \\
\hline & Yes & 46 & $21.9 \%$ \\
\hline & Total & 210 & $100.0 \%$ \\
\hline gestation age of the & 28 & 3 & $1.4 \%$ \\
\hline \multirow[t]{13}{*}{ baby(weeks) } & 30 & 3 & $1.4 \%$ \\
\hline & 31 & 2 & $1.0 \%$ \\
\hline & 32 & 9 & $4.3 \%$ \\
\hline & 33 & 1 & $0.5 \%$ \\
\hline & 34 & 4 & $1.9 \%$ \\
\hline & 35 & 6 & $2.9 \%$ \\
\hline & 36 & 15 & $7.1 \%$ \\
\hline & 37 & 9 & $4.3 \%$ \\
\hline & 38 & 26 & $12.4 \%$ \\
\hline & 39 & 62 & $29.5 \%$ \\
\hline & 40 & 62 & $29.5 \%$ \\
\hline & 41 & 8 & $3.8 \%$ \\
\hline & Total & 210 & $100.0 \%$ \\
\hline non breastfeeding & No & 199 & $94.8 \%$ \\
\hline within one hour & Yes & 11 & $5.2 \%$ \\
\hline after birth & Total & 210 & $100.0 \%$ \\
\hline Early hospital & No & 199 & $94.8 \%$ \\
\hline \multirow[t]{2}{*}{ discharge } & Yes & 11 & $5.2 \%$ \\
\hline & Total & 210 & $100.0 \%$ \\
\hline \multirow[t]{3}{*}{ Cephalohematoma } & No & 209 & $99.5 \%$ \\
\hline & Yes & 1 & $0.5 \%$ \\
\hline & Total & 210 & $100.0 \%$ \\
\hline
\end{tabular}

Table 3 displays the neonatal risk factors of jaundice. For $\mathrm{ABO}$ and other blood group incompatibilities, the majority [200 (95.2\%)] were not presenting it. A significant number of new- borns160 (76.2\%) did not present with any kind of infection. Approximately 46 $(21.9 \%)$ presented with prematurity and 164 $(78.1 \%)$ were not. For gestation age of the baby (weeks), 3 (1.4\%) were having 28 weeks, $3(1.4 \%)$ were having 30 weeks, 2 $(1.0 \%)$ were having 31 weeks, $9(4.3 \%)$ were having 32 weeks, $1 \quad(0.5 \%)$ was having 33 weeks, 4(1.9\%) were having 34 weeks, 6 $(2.9 \%)$ were having 35 weeks, $15(7.1 \%)$ were having 36 weeks, 9 (4.3\%) were having 37 weeks, 26 (12.4) were having 38 weeks, 62 $(29.5 \%)$ were having 39 weeks, 62 (29.5\%) were having 40 weeks, 8 (3.8\%) were having 41 weeks. For non-breastfeeding within one hour after birth, $11(5.2 \%)$ were able to breastfeed within one hour after birth, and 199 (94.8\%) were not. For early hospital discharge, $11(5.2 \%)$ have been early discharged, and 199 (94.8\%) were not. For cephalohematoma, $1(0.5 \%)$ newborn was presenting it, and 209 (99.5\%) were not.

\section{Risk Factors Associated with Neonatal Jaundice}

Table 4 displays the association between maternal and neonatal risk factors with neonatal jaundice. Demographic factors associated with neonatal jaundice were birth weight $(\mathrm{p}=0.015)$ and neonatal gender $(p=0.004)$. Regarding maternal risk factors, there was a significant association between the method of delivery $(p=0.000)$ and neonatal jaundice. For neonatal risk factors, factors with significant associations were gestational age of the new born $(\mathrm{p}=.002)$, $\mathrm{ABO}$ and other blood group incompatibilities $(\mathrm{p}=0.001)$, infections $(\mathrm{p}=0.000)$ and prematurity $(p=0.017)$. 
Table 4. Factors associated with neonatal Jaundice $(N=210)$

\begin{tabular}{|c|c|c|c|}
\hline Characteristics & Presence of jaundice & No jaundice & P value \\
\hline \multicolumn{4}{|c|}{ Demographic characteristics of neonates } \\
\hline \multicolumn{3}{|c|}{\begin{tabular}{l|l|l|} 
Number of days of the new-born admitted in & \\
neonatal unit
\end{tabular}} & \multirow{3}{*}{.150} \\
\hline 1 to 7 days & $76(36 \%)$ & $100(48 \%)$ & \\
\hline Less than 7 days & $17(8 \%)$ & $17(8 \%)$ & \\
\hline \multicolumn{3}{|l|}{ Neonatal Gender } & \multirow{3}{*}{.004} \\
\hline Female & $41(19 \%)$ & $42(20 \%)$ & \\
\hline Male & $52(25 \%)$ & $75(36 \%)$ & \\
\hline \multicolumn{4}{|l|}{ Birth weight } \\
\hline 1501 to $2000 \mathrm{~g}$ & $0(0)$ & $1(0.5 \%)$ & \multirow{3}{*}{.015} \\
\hline 2001 to $2500 \mathrm{~g}$ & $16(8 \%)$ & $46(22 \%)$ & \\
\hline 2501 to $3000 \mathrm{~g}$ & $77(37 \%)$ & $70(33 \%)$ & \\
\hline \multicolumn{4}{|c|}{ Maternal risk factors } \\
\hline \multicolumn{4}{|l|}{ Maternal age } \\
\hline 15 to 24 years & $14(7 \%)$ & $32(15 \%)$ & \multirow{3}{*}{.255} \\
\hline 25 to 34 years & $62(30 \%)$ & $69(33 \%)$ & \\
\hline 35 years and greater & $17(8 \%)$ & $16(8 \%)$ & \\
\hline \multicolumn{4}{|l|}{ Method of Delivery } \\
\hline Natural & 32 & 72 & \multirow[t]{2}{*}{.000} \\
\hline C section & 61 & 45 & \\
\hline \multicolumn{4}{|l|}{ ABO incompatibilities } \\
\hline Yes & $3(1.4 \%)$ & $0(0 \%)$ & \multirow[t]{2}{*}{.147} \\
\hline No & $90(43 \%)$ & $117(56 \%)$ & \\
\hline \multicolumn{4}{|c|}{ Premature rupture of membranes } \\
\hline Yes & $1(0.5 \%)$ & $0(0 \%)$ & \multirow[t]{2}{*}{.532} \\
\hline No & $92(44 \%)$ & $117(56 \%)$ & \\
\hline \multicolumn{4}{|c|}{ Neonatal risk factors } \\
\hline \multicolumn{3}{|c|}{ Gestation age of the new-born } & \multirow{4}{*}{.002} \\
\hline 28 to 32 weeks & $2(1 \%)$ & $15(7 \%)$ & \\
\hline 33 to 36 weeks & $8(4 \%)$ & $18(9 \%)$ & \\
\hline More than 37 weeks & $83(39 \%)$ & $84(40 \%)$ & \\
\hline \multicolumn{4}{|l|}{ Infections } \\
\hline Yes & $37(18 \%)$ & $13(6 \%)$ & \multirow[t]{2}{*}{.000} \\
\hline No & $56(27 \%)$ & $104(49 \%)$ & \\
\hline \multicolumn{4}{|l|}{ Prematurity } \\
\hline Yes & $12(6 \%)$ & $34(16 \%)$ & \multirow[t]{2}{*}{.017} \\
\hline No & $81(38 \%)$ & $83(40 \%)$ & \\
\hline Non breastfeeding w & & & \\
\hline Yes & $5(2 \%)$ & $6(3 \%)$ & .858 \\
\hline No & $88(42 \%$ & $111(53 \%)$ & \\
\hline ABO and other blood & & & \\
\hline Yes & $10(5 \%)$ & $0(0 \%)$ & .001 \\
\hline No & $83(39 \%)$ & $117(56 \%)$ & \\
\hline Early Hospital discha & & & \\
\hline Yes & a2 (1\%) & $9(4 \%)$ & .107 \\
\hline No & $91(42 \%)$ & $108(51 \%)$ & \\
\hline Presence of cephalo & & & \\
\hline Yes & $0(0)$ & 1 & .505 \\
\hline No & $93(44 \%)$ & $116(55 \%)$ & \\
\hline
\end{tabular}




\section{DISCUSSION}

\section{Prevalence}

The prevalence of neonatal jaundice was high as evidenced with $44.3 \%$ of newborns developing neonatal jaundice. The present study was in contrast to what has been found in the study conducted in Nigeria on the prevalence of neonatal jaundice in Eku Baptist community Hospital in Delta State, which showed that $70.5 \%$ of newborns developed neonatal jaundice within the first week of life.[11] For the gender, among jaundiced neonates, according to the cross-tabulation, males constituted a high number $127(60.5 \%)$. Males were higher in number than females. This finding shows that male infants are more susceptible to neonatal jaundice than female infants in the present study, in contrast to a study in Ibadan, which found that jaundiced female infants were presenting a significantly higher number (53.9\%) than male infants.[12] Similarly to the study conducted in Nigeria on the of neonatal jaundice in a Community Hospital in Delta State showed that male newborns presented in higher numbers $67.4 \%$ with jaundice than females.[11]

This finding is similar to a study on the incidence, risk factors, and outcome of G6PD among newborns presenting with hyperbilirubinemia in a tertiary care hospital in Punjab, which found jaundice was more prevalence in male infants $68.45 \%$ than female infants.[13] For the birth weight, the majority of jaundiced neonates were $2501 \mathrm{~g}-3000 \mathrm{~g} 147(70 \%)$. This finding is similar to a study at Ruhengeri Hospital in Rwanda, which showed that the majority $(72 \%)$ of jaundiced newborns were higher than 2500 $\mathrm{g}$ at birth.[3]

\section{Risk factors associated with neonatal jaundice}

Birth weight, neonatal gender, ABO and other blood group incompatibilities, infections, prematurity, gestation age of the baby and the $\mathrm{C} /$ Section as a method of delivering were predominant associated risk factors with neonatal jaundice. Almost the same risk factors have been found in the study conducted in Nigeria in the Eku Baptist Community Hospital in Delta State, which showed that neonatal jaundice is related to sepsis, anemia, prematurity, ABO incompatibility and lack of breastfeeding.[11] A study conducted on the magnitude of neonatal jaundice and its associated factor in NICUs in Mekelle City Public Hospitals in Northern Ethiopia, infections were associated with neonatal jaundice.[6]

A study conducted in a tertiary care hospital in India indicated prematurity was associated with neonatal jaundice,[14] and septicemia. Similarly, a study in the Federal Medical Centre Abakaliki, Southeast Nigeria.[15] A study conducted on heliotherapy for neonatal hyperbilirubinemia in Southwest, Nigeria, blood incompatibility was associated with severe neonatal jaundice.[17] A study conducted on when babies turn yellow in Singapore, found liver disease, bruising, and metabolic disorders were associated with neonatal jaundice.[15] In Iran, a study found idiopathic jaundice, ABO incompatibility, Rh incompatibility, and G6PD deficiency as risk factors associated with neonatal jaundice.[5] A study in Southern Nepal showed that male sex, LBW, breastfeeding patterns, warm ambient temperature, primipara, skilled birth provider, place of delivery, prolonged labor, oil massage, paternal education, and ethnicity were critical risk factors.[10] At the National District Hospital in Bloemfontein, normal vaginal delivery was the only risk factor associated with neonatal jaundice.[1]

In contrast, a study conducted on risk factors for severe neonatal hyperbilirubinemia in LMIC showed that risk factors such as race, social class, primiparity, sibling treated for jaundice, LBW, and weight loss associated with severe neonatal jaundice.[9] In contrast, risk factors for Malaysian neonates included gender, birth weight, and gestation age of neonates were not associated with neonatal jaundice.[16] The study conducted on pregnancy obesity associated with hyperbilirubinemia in neonates with a high prevalence in Hawaiians and Pacific Island women, showed that obesity in pregnancy is associated with neonatal jaundice.[17] In the study conducted on the burden and management of neonatal jaundice in Nigeria, G6PD deficiency was a significant risk factor associated with neonatal jaundice.[20]

\section{Limitations}

As the study was retrospective for only admitted newborns in the neonatal unit in 2016-2018, it cannot be generalized to other areas. The investigator had many challenges with incomplete, missing, and inaccurate documentation in the NICU registers and neonatal files. The poor recordkeeping was a big problem with the files. For example, the blood group of the mother and newborn were absent, the time of membrane rupture was missing in files, and the time of yellow color occurrence was missing in most of the files. Other information, such as the use of contraception during pregnancy, was missing. 


\section{CONCLUSION}

$\mathrm{ABO}$ and other blood group incompatibilities, infections, prematurity, gestational age of the baby, and the cesarean as a method of delivery were predominant associated risk factors with neonatal jaundice. There is a need for conducting further research on prevalence and risk factors associated with neonatal jaundice in other districts of Rwanda as it remains a challenge. Health care providers who work with neonates should play an essential role in identifying risk factors associated with neonatal jaundice on time and prevent their occurrence where possible. Health education is vital for the parents for the early detection of neonatal jaundice. Regular antenatal care must be done for all pregnant women, and the extended stay in the hospital after newborn birth can play an essential role in preventing neonatal jaundice. There must be more training of health care providers, especially nurses and midwives, in early diagnosis of the risk factors of neonatal jaundice. Guidelines and protocols about neonatal jaundice must be available in order to provide appropriate care to jaundiced newborns.

\section{Acknowledgments}

Many thanks to Dr Pamela Meharry for providing helpful orientation to the publication process.

This article is published open access under the Creative Commons Attribution-NonCommercial NoDerivatives (CC BYNCND4.0). People can copy and redistribute the article only for noncommercial purposes and as long as they give appropriate credit to the authors. They cannot distribute any modified material obtained by remixing, transforming or building upon this article. See https://creativecommons.org/licenses/by-ncnd/4.0/

\section{REFERENCES}

1. Brits, H., Adendorff, J., Huisamen, D., Beukes, D., Botha, K., Herbst, H., \& Joubert, G. (2018). The prevalence of neonatal jaundice and risk factors in healthy term neonates at National District Hospital in Bloemfontein. African Journal of Primary Health Care and Family Medicine, 10(1), 16.

https://doi.org/10.4102/phcfm.v10i1.1582

2. Olusanya BO, Teeple S, Kassebaum NJ. The contribution of neonatal jaundice to global child mortality: findings from the GBD 2016 study. Pediatrics. 2018 Feb 1;141(2).

3. Bonnette UL, Alexis N, Francois NN. Evaluation of bilirubin and risk of pathologic hyperbilirubinemia levels in newborns at Ruhengeri Hospital. 2017;1(D):88-96.
4. Ullah, S., Rahman, K., \& Hedayati, M. (2016, May 25). Hyperbilirubinemia in neonates: Types, causes, clinical examinations, preventive measures and treatments: A narrative review article. Iranian Journal of Public Health. Iranian Journal of Public Health.

5. Health MOF. Republic of Rwanda National Neonatal. 2014;(September).

6. Boskabadi, H., Ashrafzadeh, F., Azarkish, F., \& Khakshour, A. (2015). Complications of neonatal jaundice and the predisposing factors in newborns. Journal of Babol University of Medical Sciences, 17(9), 7-13. https://doi.org/10.22088/jbums.17.9.7

7. Lake EA, Abera GB, Azeze GA, Gebeyew NA, Demissie BW. Magnitude of Neonatal Jaundice and Its Associated Factor in Neonatal Intensive Care Units of Mekelle City Public Hospitals, Northern Ethiopia. International journal of pediatrics. $2019 \mathrm{Apr}$ $10 ; 2019$.

8. Kuzniewicz MW, Wickremasinghe AC, Wu YW, McCulloch CE, Walsh EM, Wi S, Newman TB. Incidence, etiology, and outcomes of hazardous hyperbilirubinemia in newborns. Pediatrics. 2014 Sep 1;134(3):504-9.

9. Greco, C., Arnolda, G., Boo, N. Y., Iskander, I. F., Okolo, A. A., Rohsiswatmo, R., ... Coda Zabetta, C. D. (2016, September 1). Neonatal Jaundice in Low- and Middle-Income Countries: Lessons and Future Directions from the 2015 Don Ostrow Trieste Yellow Retreat. Neonatology. S. Karger AG. https://doi.org/10.1159/000445708

10. Olusanya, B. O., Osibanjo, F. B., \& Slusher, T. M. (2015). Risk factors for severe neonatal hyperbilirubinemia in low and middleincome countries: A systematic review and meta-analysis. PLoS ONE, 10(2). https://doi.org/10.1371/journal.pone.011 7229

11. Darmstadt GL, Tielsch JM. TMI_12189_Manuscript Page 1 of 25.

12. Kolawole, S. E., Obueh, H. O., \& Okandeji Barry, O. R. (2016). Prevalence of neonatal jaundice in Eku Baptist Community Hospital in Delta State Nigeria. Journal of Public Health and Epidemiology, 8(5), 8790. 
https://doi.org/ 10.5897/jphe2015.0779

13. Serifat FA, U CA, \&tongo O. Prevalence and factors associated with neonatal jaundice: a case study of university college hospital, Ibadan. IOSR J Dent Med Sci [Internet]. 2015;14(4):2279-861. Available from: www.iosrjournals.org

14. Singh K, Singh P, Sagar M, Mehra V, Neki NS. Incidence, etiological risk factors and outcome of glucose-6 phosphate dehydrogenase deficiency (G6PDD) among neonates presenting with hyperbilirubinemia in tertiary care hospital, Punjab. Internatioanl Journal of Current Research in Medical Scienecs. 2017;3(3):6271.

15. Shetty A, Kumar BS. A study of neonatal hyperbilirubinemia in a tertiary care hospital. International Journal of Medical Science and Public Health. 2014 Oct 1;3(10):1289-93.

16. Onyearugha CN, Onyire BN, Ugboma HAA. Neonatal jaundice: Prevalence and associated factors as seen in Federal Medical Centre Abakaliki, Southeast Nigeria. J Clin Med Res [Internet]. 2011;3(3):40-5. Available from: http://www.academicjournals.org/JCMR
17. Ng MCW, How $\mathrm{CH}$. When babies turn yellow. Singapore Med J. 2015;56(11):599-603.

18. Wong F, Boo N, Othman A. Risk factors associated with unconjugated neonatal hyperbilirubinemia in Malaysian neonates. Journal of tropical pediatrics. 2013 Aug $1 ; 59(4): 280-5$.

19. Rougée LR, Miyagi SJ, Collier AC. Obstetric obesity is associated with neonatal hyperbilirubinemia with high prevalence in native hawaiians and pacific island women. Hawai'i Journal of Medicine \& Public Health. 2016 Dec;75(12):373.

20. Olusanya, B. O., Osibanjo, F. B., Mabogunje, C. A., Slusher, T. M., \& Olowe, S. A. (2016, January 1). The burden and management of neonatal jaundice in Nigeria: A scoping review of the literature. Nigerian Journal of Clinical Practice. Medknow Publications.

https://doi.org/10.4103/1119-

3077.173703 